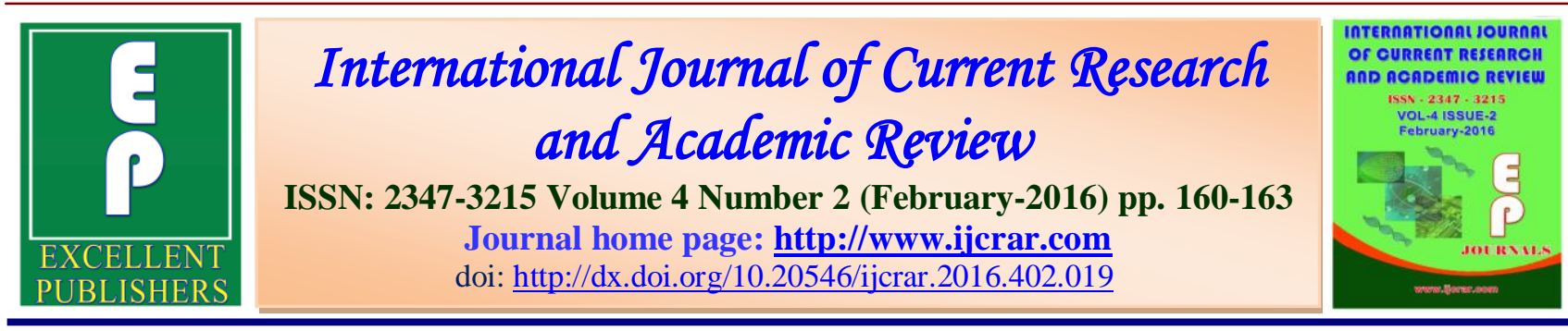

\title{
Colour Doppler Study of ovarian blood vessel in threatened abortion and comparison with asymptomaic normal pregnancy
}

\author{
Ruchika Garg*, Rachna Agarwal, Mukul Chandra, Meenal Jain and Sadhana Singh \\ Department of Obstetrics and Gynaecology, S.N.Medical, College, Agra, U.P, India
}

*Corresponding author

\begin{tabular}{|l|l|}
\hline \multirow{2}{*}{$\begin{array}{l}\text { KEYWORDS } \\
\text { Ovarian blood vessel, } \\
\text { Asymptomaic normal } \\
\text { pregnancy }\end{array}$} & $\begin{array}{l}\text { A B S T R A C T } \\
\text { in threatened abortion by Transvagimal colour Doppler ultrasound and to } \\
\text { compare it with normal asymptomatic pregnancy, with gestational age } \\
\text { ranging from 5 week to } 16 \text { weeks of pregnancy. We enrolled } 120 \text { patient from } \\
\text { August } 2011 \text { to Sep 2013. Patient were divided in two groups according to } \\
\text { the symptoms. One was study group (patients who presented here with } \\
\text { features of threatened abortion) and other was control group with normal } \\
\text { asymptomatic pregnancy. Ovarian velocimetric pattern was found abnormal } \\
\text { in 37\% of untreated patient who fail to continue pregnancy while 63\% patient } \\
\text { were able to continue pregnancy with abnormal ovarian velocimetric pattern } \\
\text { after taking treatment, 21\% of asymptomatic pregnancy shows abnormal } \\
\text { wave forms with resistivity Index of 0.77 to 0.98, Which were treated timely } \\
\text { before the appearance of symptoms and continue pregnancy till term. So } \\
\text { higher the resistivity index of ovarian vessels higher the chances of } \\
\text { miscarriage. Colour Doppler ultrasound is a safe, painless, non invasive } \\
\text { diagnostic test, which seems to be very helpful in prevention of future fetal } \\
\text { losses in asymptomatic symptomatic as well as in patient, at very early } \\
\text { gestational age. }\end{array}$
\end{tabular}

\section{Introduction}

The advent of sonography has changed the practice of obstetrics by providing a window to the womb through which anatomic structure of the fetus can be evaluated $(1,2)$. The addition of Doppler flow studies of maternal \& fetal vessels has provided a tool where the physiology of maternal-fetal unit can be assessed $(3,4)$. The utilization of real time scanning and improvement in image resolution following the introduction of high frequency probes have enabled accurate diagnosis and revolutionized the diagnostic 
as well as therapeutic management of different clinical conditions (5).

The first twelve weeks of intra uterine life are the most crucial period which needs a careful eye on the growing fetus inside and if bleeding occurs at this stage history and clinical examination may frequently be inconclusive (6).

Colour Doppler ultrasound plays a role of utmost importance in confirming the pregnancy, site of pregnancy, viability and also in predicting whether a pregnancy has a good chance of continuing or it is destined to fail. Colour Doppler study of ovarian blood vessels performed in early pregnancy can be helpful in predicting the risk of miscarriage and also helpful in choosing the management modality in patient with threatened abortion.

\section{Materials and Methods}

The present study was carried out on 120 married women with gestational age of 5-16 week of pregnancy from Agra or nearby area, who attended Antenatal clinic or admitted in the labour room during emergency in the department of Obstetrics and Gynaecology S.N. Medical College Agra. The study was carried out during the period of August 2011 to Sep 2013. Approval of ethical committee of hospital was obtained. The patient were divided in to two groups. One was study group which include those patients who visited hospital after having signs and symptoms threatened abortion another group was control group which include those female who were having normal pregnancy without any symptom.

Detail history was taken and through examination was done in all the patients, while per-speculum examination was done in patient who presented with bleeding pervaginum.

Transvaginal Doppler ultrasound was done in all the patients, to see the velocimetric pattern of ovarian blood vessels. Patients with abnormal velocimetric pattern were called for follow up every weekly till next 8 weeks or till normal pattern achieved.

\section{Results and Discussion}

During this study total 120 patients underwent Doppler ultrasound of ovarian blood vessels along with obstetrical ultrasound examination at our institution. Maternal age at the time of first visit was $(27.27 \pm 2.7)$ in study group while $(26 \pm 2.6)$ in control group. There were no significant differences between study and control group regarding maternal age, parity, Gestational age. $^{2}$ From study group mean of duration of bleeding per-vaginum was $17 \mathrm{hrs}$. The symptoms of threatened abortion such as vaginal bleeding, brownish discharge with or without cramping were detected in $17 \%$ while $29 \%$ did not have any symtoms. The "silent hematoma" in these cases was diagnosed only by ultrasound. ${ }^{2,3}$

Table 2 Present Gestational Sacpattern which includes Turgidity, Regularity of Sac, Yolk Sac. In study group $67 \%$ patients had good turgidity while in control group $83.3 \%$ patients had good turgidity. In control group $80 \%$ had regular pattern of gestational Sacwhile in study group $66.7 \%$ patient had regular pattern, Yolk sacwas found normal in $87 \%$ control group and $70 \%$ in study group. 4

Table 3 Shows that 22 cases from study group aborted with mean resistivity index of $(0.91 \pm 0.01)$ while 38 cases continue their pregnancy with mean resistivity index of $(0.78 \pm 0.01)$. These are statistically significant that higher the resistivity index, higher the chances of miscarriage. All 
Int.J.Curr.Res.Aca.Rev.2016; 4(2): 160-163

patients of abnormal velocimetric pattern were kept on progesterone support after 12 weeks of pregnancy and before this injection

human chorionic gonadotropin (HCG) was given, with advice to take rest. $5,6,7$

Table.1 Distribution of Cases According to Sociodemographic Variables

\begin{tabular}{|l|l|l|}
\hline Variables & Study group & Control group \\
\hline Maternal age & $27.27 \pm 2.7$ & $25.92 \pm 2.6$ \\
\hline Parity & 2.6 & 2.7 \\
\hline Gestational age & 9.77 & 10.62 \\
\hline Duration of bp/v & $17 \mathrm{HRS}$ & - \\
\hline Income & $54,69.8$ & 3700 \\
\hline Pelvic pain & 16 CASES & - \\
\hline
\end{tabular}

Table.2 Distribution of Cases According to Gestational Pattern

\begin{tabular}{|c|c|c|c|c|c|c|c|c|}
\hline \multirow{2}{*}{\multicolumn{2}{|c|}{ Gestational sacpattern }} & \multicolumn{2}{|c|}{ Study Group } & \multirow{2}{*}{\multicolumn{2}{|c|}{ Total }} & \multicolumn{2}{|c|}{ Control Group } & \multirow[t]{2}{*}{ Total } \\
\hline & & $\mathrm{No}$ & $\%$ & & & $\mathrm{No}$ & $\%$ & \\
\hline \multirow[t]{2}{*}{ Turgidity } & G & 40 & 66.67 & 6 & 0 & $\begin{array}{ll}5 & 0\end{array}$ & 83.33 & \multirow[t]{2}{*}{$6 \quad 0$} \\
\hline & $\mathrm{o}$ & 20 & 33.33 & & & & 16.67 & \\
\hline \multirow[t]{2}{*}{ Regularity of sac } & 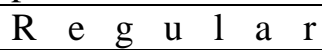 & 40 & 66.67 & 6 & 0 & 48 & 80.00 & \multirow[t]{2}{*}{6} \\
\hline & I $\mathrm{r}$ r e g u l a r & 20 & 33.33 & & & & 20.00 & \\
\hline \multirow[t]{3}{*}{ Y o l k s a c } & $\begin{array}{llllll}\mathrm{N} & \mathrm{o} & \mathrm{r} & \mathrm{m} & \mathrm{a} & 1\end{array}$ & 2 & 70.00 & 6 & 0 & 52 & 86.67 & \multirow[t]{3}{*}{6} \\
\hline & Condensed or ill defined & 10 & 16.67 & & & 4 & 6.67 & \\
\hline & $\mathrm{V} . \quad \begin{array}{lllll} & \mathrm{a} & \mathrm{r} & \mathrm{g} & \mathrm{e} \\
\end{array}$ & 8 & 13.33 & & & 4 & 6.67 & \\
\hline
\end{tabular}

Table.3 Distribution of Cases in Study Group According to Ri of Ovarian Artery

\begin{tabular}{|c|c|c|c|c|c|}
\hline Category & No. of cases & Mean of RI & SD & t-value & p-value \\
\hline $\begin{array}{l}\text { Cases who } \\
\text { continue } \\
\text { pregnancy } \\
\text { normally }\end{array}$ & 38 & 0.75 & 0.01 & \multirow[t]{2}{*}{-48.5256} & \multirow[t]{2}{*}{$<0.0001 *$} \\
\hline $\begin{array}{l}\text { Cases who } \\
\text { aborted }\end{array}$ & 22 & 0.91 & 0.01 & & \\
\hline
\end{tabular}

Table.4 Comparion of Ri of Ovarian Artery in Study Group and Control Group

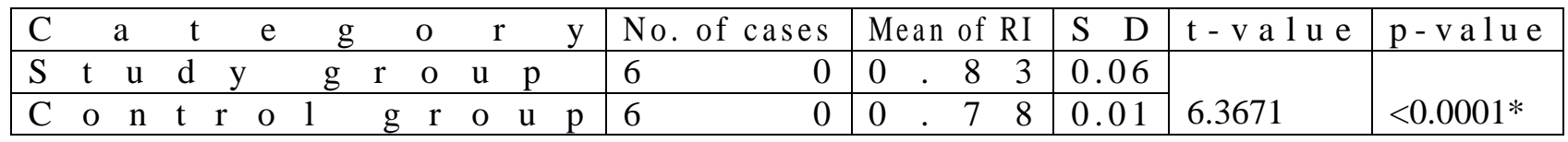

In control group resistivity index mean was found $(0.78 \pm 0.01)$, which is in favour of good outcome of pregnancy. Due to introduction of non-invasive technology of
Doppler ultrasound, it is now possible to study the flow of blood in vessels, along with other fetal parameters, In study group mean resistivity index of ovarian vessels 
was at higher side $(0.83 \pm 0.06)$. Out of 60 patients, 38 patients continue their pregnancy, while 22 cases aborted due to lack of follow up and inadequate treatment taken by the patients, In control group few cases found of having higher resistivity index of ovarian blood vessels, with abnormal velocimetric pattern and irregular fetal parameters, they were treated and prevented from future miscarriage and continue their pregnancy till term.

\section{Conclusion}

It is concluded that colour doppler study of ovarian blood vessels during normal asymptomatic early pregnancy seems to be useful and non invasive method of diagnosing impending abortion. It seems to be useful in the assessment of prognosis and management of threatened abortion. Resistivity index of ovarian blood vessels are utmost clinical implication to screen impending abortion and this may help us in establishing the basis to study the abnormalities in early pregnancy. But we must acknowledge the limitations of our sample size and suggest a larger study to refuse and reaffirm usefulness of colour doppler in ovarian blood vessels as a monitor in early pregnancy.

\section{References}

1. Burn PN. The physics of Doppler. In Chervenak FA, Isaacsar GC, Campbell
$S$ (Eds) : Ultrasound in Obstetrics and Gynaecology, Boston, Little, Brown \& Co. 1993.

2. Sander Nagy, Melissa Bush, Joanne Stone, Robert H, Lipinski and Sandor Gardo. Clinical significance of subchorionic and retroplacental haematoma detected in the first trimester of pregnancy. Obst. Gynecol 2003; 102: 94-100.

3. Jouppila P. clinical consequences after ultrasonic diagnosis of intrauterine hematoma in threatened abortion. J. Clin Ultrasound, 1985; 13: 107-11.

4. Dongol A, Mool S, Timaeir P. Outcome of pregnancy complicated by threatened abortion. Kathmandu Univ Med J 2011; 33(1): 41-44.

5. Beu-Haroush A, Yogev Y, Mashiach R, Meizner I. Pregnancy outcome of threatened abortion with subchorionic hematoma possible benefit of bed rest? Isec Med Assoc. J. 2003; 5: 422-4.

6. Giobbe M, Fazzio M, Boui T. Current role of bed rest in threatened abortion. Minerva Gynecol 2001; 53: 337-40.

7. Igor Hudic, Zlatar Fatusic. Progesterone induced blocking factor (PIBF) and Th1/Th2 cytokine in women with threatened abortion. J Perinat Med 2009; 37: 338-42.

\section{How to cite this article:}

Ruchika Garg, Rachna Agarwal, Mukul Chandra, Meenal Jain and Sadhana Singh. 2016. Colour Doppler Study of ovarian blood vessel in threatened abortion and comparison with asymptomaic normal pregnancy. Int.J.Curr.Res.Aca.Rev. 4(2): 160-163.

doi: http://dx.doi.org/10.20546/ijcrar.2016.402.019 